\title{
FORMAÇÃO DOCENTE PARA A DIVERSIDADE: UM SABER PLURAL
}

\author{
C.A. GUERCH \\ Instituto Federal Farroupilha \\ cris.direito.federal.26@gmail.com
}

Artigo submetido em 07/09/2017 e aceito em 19/07/2019

DOI: $10.15628 /$ holos.2019.6272

\section{RESUMO}

O presente artigo tem por objetivo investigar se as temáticas de gênero e diversidade são abordadas na formação inicial docente nos Cursos de Licenciatura do Instituto Federal de Educação, Ciência e Tecnologia Farroupilha. Ainda, qual o peso que essa formação traz para a construção do saber docente, este analisado a partir das perspectivas de Tardif (2011), Imbernón (2005) e Cunha (2010). O trabalho docente constitui-se de sua prática a qual é construída a partir dos saberes que o docente adquire ao longo de sua vida, ante as relações que produz com seus colegas, com discentes e sociedade. Por isso, o exercício da docência supõe necessariamente um processo de formação permanente e que estimule os profissionais a serem protagonistas nesse processo de (re) significação de concepções culturais e históricas ainda muito arreigadas às discriminações. Utilizando-se de uma metodologia qualitativa, a partir de um procedimento de investigação documental, onde foram analisados os Projetos Pedagógicos de Curso, buscar-se-á refletir acerca das questões de formação docente e a construção dos saberes que fazem parte do construto pessoal de cada docente. Essa pesquisa confirmou a necessidade de que a formação inicial dos licenciandos contemple, de forma ainda mais ampla, as temáticas de gênero e diversidade, já que ao atuar dentro do ambiente escolar, local de tantas heterogeinidades, o docente necessita subsídios reflexivos e críticos para saber abordar tais temáticas e conseguir elaborar espaços de discussão e promoção de uma educação que combata as discriminações e não reproduza estereótipos.

PALAVRAS-CHAVE: Diversidade; Formação docente; Gênero.

\section{EDUCATIONAL TRAINING FOR DIVERSITY: A PLURAL KNOWLEDGE}

\begin{abstract}
The purpose of this article is to investigate whether gender and diversity issues are addressed in initial teacher education in the Federal Institute of Education, Science and Technology Farroupilha. Still, what weight does this training bring to the construction of teaching knowledge, which is analyzed from the perspective of Tardif (2011), Imbernón (2005) and Cunha (2010). The teaching work is constituted of its practice which is constructed from the knowledge that the teacher acquires throughout his life, before the relations he produces with his colleagues, with students and society. For this reason, teaching is necessarily a process of permanent formation and that encourages professionals to be protagonists in this process of (re) signification of cultural and historical conceptions still very much
\end{abstract}

related to discrimination. Using a qualitative methodology, from a documental research research procedure, where the Pedagogical Projects of the Course were analyzed, we will seek to reflect on the issues of teacher training and the construction of the knowledge that is part of the construct Of each teacher. This research confirmed the need for the initial training of undergraduates to contemplate, in a broader way, the themes of gender and diversity, from the moment that the teacher acting within the school environment, a place of so many heterogeneities, must have some subsidy Reflective and critical in order to know how to approach such topics and to elaborate spaces for discussion and promotion of an education that combats discrimination and does not reproduce stereotypes.

KEYWORDS: Diversity; Teacher training; Genre. 


\section{INTRODUÇÃO}

O ambiente escolar além de espaço de aprendizagem, conhecimento, inter-relações, é também local que reproduz modelos de socialização com muitas questões culturais e históricas extremamente arreigadas de significado e que são mediadas pelos educadores, haja vista a extensão de atuação da escola.

O processo educacional suscita debates que problematizem padrões atuantes na construção de práticas discriminatórias, fato este que faz com que se perceba que a formação docente precisa pensar a realidade da escola, estando as questões de gênero e diversidade latentes no cotidiano escolar e, portanto, fazendo-se necessária sua inserção na formação inicial.

Nesse sentido, valorizando o espaço escolar em sua plenitude, bem como considerando que este local de atuação docente precisa estar lapidado para receber toda a diversidade cultural, econômica, social, sexual, religiosa é que este artigo instiga a reflexão acerca da formação inicial docente enquanto meio de promoção de discussão e problematização sobre os saberes docentes envolvidos nesta demanda escolar, a partir da atuação do docente enquanto mediador nesse processo ainda crescente de discriminação e preconceito no espaço escolar.

Buscando instrumentalizar a discussão, a pesquisa terá por objeto a análise dos Projetos Pedagógicos de Curso do Instituto Federal Farroupilha, mais especificamente em componentes curriculares e suas bibliografias, visando investigar se essa Instituição de Ensino insere as temáticas de gênero e diversidade na formação inicial de seus futuros docentes, com o intuito de embasar a discussão sobre a promoção, ou não, dentro da Educação Profissional e Tecnológica, de meios de instigar os educandos a buscarem em sua formação subsídios para atuarem em sua carreira.

Ainda, analisando os saberes necessários ao docente para atuação completa e que atenda as demandas, será utilizado embasamento teórico de diversos autores que estudam sobre saberes docentes e buscar-se-á refletir sobre a importância da formação inicial para construir esses saberes.

Assim, percebendo que o ambiente escolar atende tantas demandas e as questões de gênero e diversidade estão inerentes a esse espaço social, fundamental que os docentes já desde sua formação inicial tenham ferramentas para atuação e, mais do que uma base conteudista, tenham atuação dentro da realidade acerca desses temas, contribuindo para a construção do docente dentro da perspectiva de um saber plural e social, atrelado ao trabalho dos demais colegas, em um sistema colaborativo e que busca uma formação integral e humana aos educandos.

\section{OBJETO DE PESQUISA}

A pesquisa utilizou como objeto o estudo dos Projetos Pedagógicos de Curso dos Cursos de Licenciatura do Instituto Federal Farroupilha que existem na instituição desde o início de suas atividades, em 2008. 
A escolha pelo estudo dos planos de curso deu-se pois ainda se verifica na formação inicial dos docentes lacunas no que diz respeito a alguns temas latentes dentro da práxis educacional, estando as questões de gênero nesse locus. Isso porque, especialmente após a década de 90, a partir do fortalecimento das políticas públicas, promulgação da Lei de Diretrizes e Bases (1996) e criação dos Parâmetros Curriculares Nacionais para o Ensino Fundamental (1997), verificou-se como as temáticas que envolvem educação sexual e gênero são necessárias ao ambiente escolar, principalmente porque as demandas que envolvem esses temas estão intrinsicamente presentes na escola.

Tais políticas possuem por base a Constituição Federal (BRASIL, 1988), a qual em seu Art. 5 refere sobre a igualdade de direitos, bem como a Lei de Diretrizes e Bases da Educação (BRASIL, 1996) e inclusão do Sistema Nacional de Avaliação da Educação Básica (SAEB). (ROSEMBERG, 2001).

Ainda, a escolha por investigar uma Instituição de Educação Profissional e Tecnológica deu-se pois quando os Instituto Federais foram criados, através da Lei 11.892 de 29 de dezembro de 2008, em seu Art. 60 prevê que essa Instituição deve, obrigatoriamente, ofertar $20 \%$ de suas vagas para formação de professores, o que demonstra o comprometimento institucional em ofertar cursos de qualidade e que atendam a demanda educacional.

Desta forma, a pesquisa, de cunho documental, exploratória e qualitativa busca verificar se os cursos de Licenciatura do IFFar trazem em seu currículo características de uma formação voltada para o estudo das questões de gênero e diversidade, tema relevante e que certamente será enfrentado pelo docente ao longo de sua carreira profissional.

\subsection{Os Cursos de Licenciatura do Instituto Federal Farroupilha (IFFar)}

O Instituto Federal de Educação, Ciência e Tecnologia Farroupilha - IFFar - foi criado pela Lei $n^{\circ}$ 11.892, de 29 de dezembro de 2008, por meio da integração do Centro Federal de Educação Tecnológica de São Vicente do Sul, de sua Unidade Descentralizada de Júlio de Castilhos, da Escola Agrotécnica Federal de Alegrete, e do acréscimo da Unidade Descentralizada de Ensino de Santo Augusto que anteriormente pertencia ao Centro Federal de Educação Tecnológica de Bento Gonçalves (PDI, 2014, p. 14)

Atualmente o Instituto Federal Farroupilha possui a Reitoria na cidade de Santa Maria e é composto pelas seguintes unidades administrativas: Campus Alegrete, Campus Jaguari, Campus Júlio de Castilhos, Campus Panambi, Campus Santa Rosa, Campus Santo Ângelo, Campus Santo Augusto, Campus São Borja, Campus São Vicente do Sul, Campus Avançado Uruguaiana e Campus de Frederico Westphalen.

Atendendo, nos dias de hoje, a mais de 15 mil alunos, os quais estão distribuídos em todos os Campi do IFFar e que, alicerçado na legislação de sua criação, o IFFar, a partir do Art. 6o e 
70 da Lei 11.892/2008 busca atender a demanda de formação de professores para a educação básica seguindo tais diretrizes:

Art. 6o, VI - qualificar-se como centro de referência no apoio à oferta do ensino de ciências nas instituições públicas de ensino, oferecendo capacitação técnica e atualização pedagógica aos docentes das redes públicas de ensino;

Art. 7o, $\mathrm{VI}$ - ministrar em nível de educação superior: b) cursos de licenciatura, bem como programas especiais de formação pedagógica, com vistas à formação de professores para a educação básica, sobretudo nas áreas de ciências e matemática, e para a educação profissional.

Desta forma, o Instituto Federal Farroupilha dentro de sua extensão de abrangência dentro do Estado do Rio Grande do Sul se organiza e autoriza a abertura dos Cursos de Licenciatura nos Campi a partir da demanda das áreas do conhecimento, atuando especialmente nas áreas de ciências e matemática, e para a educação profissional.

\subsection{Análise dos dados}

Desde sua criação, em 2008, o IFFar foi expandindo-se a partir da abertura de novos Campi e aumentando seu leque de atuação e, na área de formação de professores, foi intensificando a abertura dos cursos, um em cada Campus, pelo menos, com o intuito de atingir a meta legal e sabendo de seu papel enquanto Instituição de Ensino criada com o viés de acesso à todos e colaborando com a qualificação dos profissionais da educação.

Organizado pela Pró-Reitoria de Ensino, os Projetos Pedagógicos de Curso foram sendo criados e implementados nos Campi a medida que foram aprovados pelo Conselho Superior da Instituição, sendo que ao longo desses nove anos de existência, algumas reformulações aconteceram e que impactaram significativamente nos cursos e a melhoria na qualidade da oferta.

Para fins de visualização, a tabela abaixo mostrará o atual panorama institucional de oferta das Licenciaturas, demonstrando o compromisso Institucional em de fato ofertar a formação de professores pensando em aumentar o contingente de docentes aptos a atuarem na educação básica.

\begin{tabular}{|c|c|c|c|}
\hline Curso & Campus & Ano de início do curso & CH \\
\hline \multirow{4}{*}{ Ciências Biológicas } & Alegrete & 2010 & 3304 \\
\cline { 2 - 4 } & Júlio de Castilhos & 2012 & 3304 \\
\cline { 2 - 4 } & Panambi & 2015 & 3304 \\
\cline { 2 - 4 } & Santo Augusto & 2015 & 3304 \\
\cline { 2 - 4 } & Santa Rosa & 2014 & 3304 \\
\hline
\end{tabular}




\begin{tabular}{|c|c|c|c|}
\hline \multirow{2}{*}{ Computação } & São Vicente do Sul & 2009 & 3304 \\
\cline { 2 - 4 } & Santo Augusto & 2009 & 3268 \\
\hline \multirow{2}{*}{ Educação do Campo } & Santo Ângelo & 2016 & 3268 \\
\hline \multirow{2}{*}{ Física } & Jaguari & 2013 & 3232 \\
\hline \multirow{3}{*}{ Matemática } & São Borja & 2011 & 3304 \\
\cline { 2 - 4 } & Alegrete & 2010 & 3376 \\
\cline { 2 - 4 } & Júlio de Castilhos & 2009 & 3376 \\
\cline { 2 - 4 } & Santa Rosa & 2010 & 3376 \\
\hline \multirow{2}{*}{ Química } & São Borja & 2011 & 3304 \\
\cline { 2 - 4 } & Alegrete & 2010 & 3304 \\
\cline { 2 - 4 } & Panambi & 2010 & 3304 \\
\hline
\end{tabular}

Fonte: Projetos Pedagógicos de Curso do IFFar

Da tabela acima pode-se inferir que desde a criação do IFFar teve início dos cursos de formação de professores, o qual possui seis áreas diferentes, com pelo menos dois cursos em cada Campus, aumentando a abrangência de possibilidades de estudos.

Tendo em vista que a lei que criou os Instituto Federais foi promulgada em dezembro de 2008, os anos seguintes foram de adaptações e muitas mudanças, uma vez que os CEFETs São Vicente do Sul e Alegrete, com mais de quarenta anos de existência, sentiram as mudanças profundas que a legislação trouxe, além do que a expansão do IFFar se intensificou, ao passo que a criação de cursos também.

Assim, no início das atividades do IFFar os Campis tinham Projetos Pedagógicos de Curso concebidos por cada Campus, com algumas discussões inter-Campi, mas que resultou em Projetos muito diferentes, atendendo muitas das especificidades locais de cada Campus.

No ano de 2013 a Pró-Reitoria de Ensino intensifica a criação de GTs (Grupos de Trabalho) com o intuito de reformulação de todos os Projetos Pedagógicos de Curso da Instituição e uniformização dos mesmos, trabalho este que trouxe frutos a partir de 2014, quando os Projetos Pedagógicos de Curso passaram a ser únicos, independente do Campus, quando o curso ofertado for o mesmo.

Então, para esta pesquisa, foram utilizados todos os Projetos Pedagógicos de Curso de Licenciatura que o IFFar possuiu ao longo destes nove anos, buscando investigar especificamente ementa de componentes curriculares e suas bibliografias para então buscar resposta para a 
indagação maior, qual seja, o IFFar, em seus cursos de formação inicial de professores, busca inserir as temáticas de gênero e diversidade nos currículos? Como ela acontece?

Desta forma, para obter a resposta dessas inquietações, a partir de toda uma análise global, obteve-se as seguintes constatações:

1) A totalidade dos cursos sofreu reformulações de diferentes ordens, interferindo diretamente na Carga Horária Total do curso e alterações de componentes curriculares;

2) Após a reformulação de 2014 houve um padronização linear dos Projetos Pedagógicos de Curso, especialmente com relação a itens que fazem parte de toda a estrutura básica dos cursos, atendidos a partir de ações Institucionais, como, por exemplo, as políticas de apoio ao discente (Assistência Estudantil, Núcleo Pedagógico Integrado (NPI), Atendimento Pedagógico, Psicológico e Social, Atividades de Nivelamento, Mobilidade Acadêmica, Programa Permanência e Êxito e Acompanhamento de Egressos);

3) Aspecto significativo que os Projetos Pedagógicos de Curso do IFFar contemplam é que se priorizará ações inclusivas com ênfase nas especificidades de determinados grupos sociais, promovendo a garantia de igualdade de condições e oportunidades educacionais: (...) "II - gênero e diversidade sexual: o reconhecimento, o respeito, o acolhimento, o diálogo e o convívio com a diversidade de orientações sexuais fazem parte da construção do conhecimento e das relações sociais de responsabilidade da escola como espaço formativo de identidades. Questões ligadas ao corpo, à prevenção de doenças sexualmente transmissíveis, à gravidez precoce, à orientação sexual, à identidade de gênero são temas que fazem parte desta política";

4) Dentro da perspectiva da Educação Inclusiva, objeto deste estudo, o IFFar avançou significativamente com a criações de Núcleos que objetivam atender a diversidade institucional, através do Núcleo de Apoio as Pessoas com Necessidades Educacionais Especiais (NAPNE), Núcleo de Estudos Afro-Brasileiros e Indígenas (NEABI) e, em 2015, a criação do Núcleo de Gênero e Diversidade Sexual (NUGEDIS); e

5) A criação da Prática enquanto Componente Curricular (PeCC) nos Cursos de Licenciatura surgiram com o viés de proporcionar experiências de articulação de conhecimentos construídos ao longo do curso em situações de prática docente; oportunizar o reconhecimento e reflexão sobre o campo de atuação docente; proporcionar o desenvolvimento de projetos, metodologias e materiais didáticos próprios do exercício da docência, entre outros, integrando novos espaços educacionais como locus da formação dos licenciandos.

Então, feitas essas considerações gerais, dialogando com as constatações feitas da análise dos documentos, foi possível perceber que após as reformulações em 2013 houve um avanço significativo de ações voltadas para atendimento de grupos considerados "minoritários", fomentando dentro dos cursos de Licenciatura a preocupação em se discutir sobre os mais diferentes temas. 
Ainda, com relação a componente curricular, de maneira geral, todos os Projetos Pedagógicos de Curso, desde 2009, contemplaram em, pelo menos um deles as questões de gênero e diversidade, na perspectiva a seguir:

Projetos Pedagógicos de Curso vigentes de 2009 a 2013: havia 13 cursos em atividade, os quais todos possuíam apenas uma única disciplina que contemplava, em sua ementa, a temática de gênero e diversidade intitulada "Educação para Diversidade e Inclusão", com Carga Horária de 60h, e que previa o trabalho sobre o cotidiano educacional a partir da "diversidade e da escola inclusiva. Acessibilidade. Pessoas com necessidades educacionais específicas. Dificuldades de aprendizagem. (...) Relações de gênero e Diversidade sexual. Educação e direitos humanos (...). Outrossim, um aspecto que chamou a atenção foi o fato de que embora a ementa atenda as questões de gênero e diversidade, a bibliografia básica e complementar não trouxe nenhuma indicação de leitura sobre os assuntos, focando especificadamente na temática de inclusão para pessoas com deficiência;

Projetos Pedagógicos de Curso vigentes a partir de 2014 (pós padronização institucional): há 16 cursos em atividade, onde todos também possuem um componente curricular que atende as temáticas de gênero e diversidade, o qual alterou a nomenclatura para "Diversidade e Educação Inclusiva", com Carga Horária de 72h, a qual traz uma ementa mais enxuta, com tópicos pontuais, como: "Diversidade e escola inclusiva (...) Políticas Afirmativas e Educação. Gênero e Educação. Educação e Diversidades (...)". A questão da bibliografia foi superada apenas no Campus Alegrete, o qual trouxe a pesquisadora de gênero e diversidades Guacira Louro como referencial de trabalho.

Assim, a partir das constatações referidas, fica evidente que o IFFar desde sua concepção buscou atender as temáticas de gênero e diversidade nos projetos pedagógicos dos cursos de Licenciatura, embora em apenas um componente curricular, o qual possui diversos temas a serem tratados, em uma carga horária de apenas 72 horas, e que, acaba sendo insuficiente ante a gama de outras questões que se insere quando se fala em gênero e diversidade no espaço escolar.

A criação das PeCC também foi ponto que agregou bastante quando se pensa a formação teórica aliada a formação prática, uma vez que "não se restringe à aplicação dos conhecimentos científicos, mas constitui um espaço de criação e reflexão acerca do trabalho docente e do contexto social em que se insere, com vistas à integração entre a formação e o exercício do trabalho docente".

Por fim, percebeu-se que, quase que predominantemente, a formação inicial do docente que ministra a disciplina de Diversidade e Educação Inclusiva é educador (a) especial, o que faz com que o foco maior da disciplina seja na educação inclusiva para alunos PCDs, ficam um pouco de lado a formação para atender às diversidades de gênero e sexo. Esse fato é corroborado pelo rol de disciplinas eletivas dos cursos, o qual na grande totalidade contempla disciplina de Libras II, reforçando o forte viés inclusivo somente para alunos PCDs. 
Desta forma, reforçando a importância de se trazer ao estudo dos licenciandos discussões sobre as temáticas de gênero e diversidade, cita-se Seffner et al (2016) os quais trazem uma visão de escola muito significativa quando se pensa a formação inicial e se situa o local que os futuros docentes irão atuar:

Escola é lugar de alfabetização científica, de aprender sobre o mundo e de preparar-se para a vida a partir de um currículo estabelecido, profissionais reconhecidos, disciplinas e projetos, calendário anual e seriação progressiva, acesso à biblioteca e a acervos, estratégias de avaliação das aprendizagens, convívio com colegas da mesma geração, encontros e trocas entre as culturas juvenis e brincadeiras e rituais de passagem. Escola é lugar de fazer perguntas e ter as perguntas respondidas em um clima de liberdade para ampliar os saberes. A escola oferta conhecimentos e busca interessar alunos e alunas no seu aprendizado através de uma diversidade de estratégias pedagógicas, configurando o que se costuma chamar de cultura escolar. $(2016$, p. 62)

Assim, dentro deste meio que busca estratégias pedagógicas para o ensinoaprendizagem, essencial que também trace estratégias para ser percursor da constituição de alunos comprometidos e capazes de pensarem sobre o meio que os rodeia e fazer conexões para com o mundo social, agregando para si novas competências, além da tradicional que é a alfabetização científica. (SCHEFFER et al, 2016)

Perceber a escola como lugar das multidiversidades e pluralidades é ponto inicial fundamental, especialmente no viés do mundo pós-moderno, tão dinâmico e desafiador, interlaçando concepções básicas da educação em relação ao aprender a ser, conviver e conhecer. (DELORS, 1994).

A partir da percepção de que o ambiente escolar é também de descobertas, novas experiências, construção de identidades que aqui há um grande e longo desafio dos educadores, seja porque a sociedade culturalmente e historicamente cobra que as pessoas tenham um identidade: masculina ou feminina, com comportamentos pré-definidos, estereótipos sociais, seja porque os profissionais não foram capacitados em sua formação inicial para isso. Fato este que reforça a necessidade de os Cursos de Licenciatura fomentarem as discussões e promoverem formação para a diversidade.

Ainda, nessa linha de pensamento, Louro (1997) refere:

Diferenças, distinções, desigualdades... A escola entende disso. Na verdade, a escola produz isso. Desde seus inícios, a instituição escolar exerceu uma ação distintiva. Ela se incumbiu de separar os sujeitos - tornando aqueles que nela entravam distintos dos outros, os que a ela não tinham acesso. Ela dividiu também, internamente, os que lá estavam, através de múltiplos mecanismos de classificação, ordenamento, hierarquização. A escola que nos foi legada pela sociedade ocidental moderna começou por separar adultos de crianças, católicos de protestantes. Ela também se fez diferente para os ricos e para os pobres e ela imediatamente separou os meninos das meninas. (1997, p. 57)

Trata-se de aceitar que a escola não está preparada para tamanha diversidade que hoje se apresenta. Ela pode aproximar as relações ou então promover maiores distanciamentos entre a diversidade que nela se apresenta. Sobre isso, Louro (1997) cita:

Currículos, normas, procedimentos de ensino, teorias, linguagem, materiais didáticos, processos de avaliação são, seguramente, loci das diferenças de gênero, sexualidade, 
etnia, classe - são constituídos por essas distinções e, ao mesmo tempo, seus produtores. Todas essas dimensões precisam, pois, ser colocadas em questão. É indispensável questionar não apenas o que ensinamos, mas o modo como ensinamos e que sentidos nossos/as alunos/as dão ao que aprendem. Atrevidamente é preciso, também, problematizar as teorias que orientam nosso trabalho (incluindo, aqui, até mesmo aquelas teorias consideradas "críticas"). Temos de estar atentas/os, sobretudo, para nossa linguagem, procurando perceber o sexismo, o racismo e o etnocentrismo que ela frequentemente carrega e institui. (1997, p. 64)

Então, significa ter atitude, trazer para si a responsabilidade de formar docentes capacitados e que tenham pelo menos alguma noção dos conceitos de gênero e diversidade, bem como consigam promover a tolerância, sendo que aqui entra a educação como cerne de um papel formador, transformador, com profissionais que busquem o aperfeiçoamento do ensino através da flexibilização de assuntos e fomento de discussões.

Sobre o reconhecimento da Escola como local oportuno e apropriado para se discutir sobre as pluralidades, Carrara (2009):

Ao discutir tais questões com os/as professores/as brasileiros/as, busca-se contribuir, mesmo que modestamente, com a escola em sua missão de formadora de pessoas dotadas de espírito crítico e de instrumentos conceituais para se posicionarem com equilíbrio em um mundo de diferenças e de infinitas variações. Pessoas que possam refletir sobre o acesso de todos/as à cidadania e compreender que, dentro dos limites da ética e dos direitos humanos, as diferenças devem ser respeitadas e promovidas e não utilizadas como critérios de exclusão social e política. (2009, p. 15)

Funda-se aqui, o quão necessário é discutir conjuntamente com todo o contexto escolar, reconhecendo que há desigualdades e diversidades, mas que frente a responsabilidade da escola na formação de cidadãos e cidadãs, precisa ter mecanismos que promovam o respeito das culturas, das sociedades e das normas. "A convivência com a diversidade implica o respeito, o reconhecimento e a valorização do/a outro/a, e não ter medo daquilo que se apresenta inicialmente como diferente. Esses são passos essenciais para a promoção da igualdade de direitos." (CARRARA. 2009, p. 32).

E por omissão a Escola não pode ser apontada, pois a educação não pode ficar imóvel perante os anseios sociais a que se está inserida. Isso porque, no interior desse novo contexto educacional, marcado pela diversidade e pelas demandas de respeito e inclusão, o professor é tanto o indivíduo que domina o conhecimento e as estratégias de ensino de uma disciplina específica como quem atua na qualidade de adulto de referência para as questões que dizem respeito aos valores que norteiam a vida no espaço público republicano. O desafio maior está dado pelo conceito de modus vivendi, capacidade de construir acordos entre indivíduos e grupos cujas opiniões difiram. (SEFFNER, 2016).

Nesse sentido, seja pela obrigatoriedade da lei, seja porque é papel inerente ao seu fim e porque a pluralidade está nela inserida (de origem, de gênero, étnico-racial, religiosa), a Escola precisa torna-se responsável por traçar os caminhos que levarão a uma educação que acolhe e elimina preconceitos, uma vez que: 
Quando a escola não oferece possibilidades concretas de legitimação das diversidades (nas falas, nos textos escolhidos, nas imagens veiculadas na escola etc) o que resta aos alunos e alunas, senão a luta cotidiana para adaptar-se ao que esperam deles/as ou conformar-se com o status de "desviante" ou reagir aos xingamentos e piadinhas e configurar entre os indisciplinados? E, por último, abandonar a escola. (CARRARA, 2009, p. 68).

Assim, essencial que a escola tenha a seu lado a família, estudantes, comunidade e Estado, em um trabalho coletivo e articulado para que possa atender as demandas e de fato formar cidadãos crítico e disseminadores da cultura de paz e tolerância.

Desta forma, quando se percebe a formação inicial docente como aspecto fundamental para os futuros desafios da carreira, essencial que as Instituições de Ensino fortaleçam essa base empírica e instigue os graduandos a se fortalecerem de ferramentas que lhes darão suporte para trabalhar diferentes situações corriqueiras, estando as questões de gênero e diversidade extremamente inseridas no ambiente escolar, precisando ser tratada e problematizada.

O imaginário construído de que a escola é espaço neutro não se sustenta, uma vez que basta olharmos ao redor para percebermos as diferenças de raça, orientação sexual, cultural, regional que transitam nesse espaço. Problematizar a esteriotipação que a escola produz é essencial, sendo o espaço de formação campo fértil para isso.

Reconhecer a diferença é um debate indispensável sobre os "potenciais e a qualidade da educação" (SILVÉRIO et al, 2010), sendo que:

As marcas negativas ou positivas que seu gênero, sua raça, sua sexualidade, sua classe, sua origem regional, sua aparência, frisaram em sua caminhada familiar, escolar, profissional, entre outras, ilustram as fragilidades do discurso estritamente meritocrático, pois demonstram o modo que o sexismo, o machismo, o racismo, a heteronormatividade e o regionalismo posicionam determinadas pessoas em um locus social de superioridade e outras em um locul social de inferioridade. (2010, p. 146)

Assim, os profissionais que atuam na escola não podem permear e reproduzir tais discriminações, sendo essencial que os currículos de licenciatura contemplem essa reflexão da realidade, com o intuito de "identificar e desconstruir os processos de composição e perpetuação do estabelecido e do diferente" (SILVÉRIO et al, 2010, p. 147) tendo uma atuação comprometida e enfrentando tais temáticas.

\section{SABERES DOCENTES: A IMPORTÂNCIA DA FORMAÇÃO INICIAL}

Quando se pensa a formação inicial em qualquer área de atuação logo se visualiza ela como alicerce na gama de conhecimentos e se imagina que ela contemplará todos as demandas e desafios da carreira profissional, o que é utopia. Isso porque a formação inicial nunca será totalmente completa, haja vista a própria dinâmica social e das relações.

Tratando-se da formação inicial docente tem-se um terreno fértil de concepções e relações, uma vez que a docência é extremamente complexa e, ao mesmo tempo, primorosa e essencial para a constituição da educação. 
Sobre a formação inicial, Pimenta (1999) refere que:

$\mathrm{Na}$ formação inicial é fundamental a produção de pesquisas em didática a serviço da reflexão dos alunos e da constituição de suas identidades como professores. Ao mesmo tempo problematizando-as diante da realidade do ensino nas escolas, buscando desenvolver no alunos um atitude investigativa. (1999, p. 17)

Verifica-se que a formação inicial deve ser momento de descobertas e, portanto, momento de questionamentos e reflexões acerca dos conhecimento que ali serão adquiridos, buscando não preocupar-se somente com questões de cunho técnico e teórico, mas sendo etapa de formação que despertará no docente aspirações e desafios que a carreira lhe mostrará.

Sobre essa etapa de construção do conhecimento, Imbernón (2011) refere:

A formação inicial deve evitar passar a imagem de um modelo profissional assistencial e voluntarista que frequentemente leva a um posterior papel de técnico-continuísta, que reflete um tipo de educação que serve para adaptar acriticamente os indivíduos a ordem social e torna o professor vulnerável ao entorno econômico, político e social. Ao contrário, dotar o futuro professor de uma bagagem sólida nos âmbitos cientifico, cultural, contextual, psicopedagógico e pessoal deve capacita-lo a assumir a tarefa educativa em toda sua complexidade, atuando reflexivamente com a flexibilidade e rigor necessários, isto é, apoiando suas ações em uma fundamentação válida para evitar cair no paradoxo de ensinar a não ensinar, ou em uma falta de responsabilidade social e política que implica todo ato educativo e em uma visão funcionalista, mecânica, rotineira, técnica, burocrática e não reflexiva da profissão, que ocasiona um baixo nível de abstração, de atitude reflexiva e um escasso potencial de aplicação inovadora. (2011, p. 62-63)

Trata-se de ter na formação inicial docente um leque enorme de possibilidades de discussões sobre a realidade, contemplando uma formação de fato heterogênea, abarcando diferentes conhecimentos e trazendo essas contribuições para a realidade vivida, haja vista que a prática docente nem sempre estará contemplada na formação inicial uma vez que é impossível se prever todas as situações de vida escolar. É, pois, ter na "formação inicial a possibilidade de uma análise global das situações educativas" (IMBERNÓN, 2011, p. 64) construindo os conhecimentos essenciais para a atuação futura.

Desta forma, contemplando as reflexões que a formação inicial contemplará e agregará na carreira docente, ela é que começará a ser a ponte inicial na construção do saber docente, este entendido, na visão Tardif (2008) como um "um saber plural, formado pelo amálgama, mais ou menos coerente, de saberes oriundos da formação profissional e de saberes disciplinares, curriculares e experienciais" (TARDIF, 2008, p.36).

Falar em saberes docentes é entrar em um campo de reflexão muito vasto, estudado por diversos pesquisadores como Pimenta (1999), Tardif (2008), Cunha (2010), Imbernón (2011), os quais buscam em suas discussões entender a dinâmica tão complexa e global que envolve a profissão docente, a qual agrega tantas relações e concepções.

Contemplando o objeto de discussão deste artigo, qual seja, se a formação inicial docente contempla questões de gênero e diversidade, Gauthier (1998) irá refletir sobre o que é pertinente saber para ensinar; o repertório de conhecimento para prática pedagógica. Quais os saberes e habilidades para o exercício da docência? Trata-se de uma "tarefa complexa, uma vez que só 
conhecer o conteúdo não é suficiente para saber ensinar" (GAUTHIER, 1998, p. 20), assim como ter talento, ter bom senso, ter intuição, ter cultura também são insuficientes, ainda mais se a formação não contemplar alguns assuntos, causando então lacunas e que futuramente cobrarão do docente o respaldo que precisa para atuar em determinadas situações. É, então, considerar que o saber docente abraça muito mais do que conhecimento de conteúdos, precisa ter simbiose com as mais diferentes áreas de atuação.

Ainda, falando em habilidades e saberes necessários, Tardif (2008) defende que o saber docente não se reduz exclusivamente a processos mentais, mas é também um saber social, o qual se manifesta nas relações complexas entre docentes e discentes, "pois é partilhado por um grupo de agentes; pois sua posse depende da legitimidade da instituição; pois os objetos e a aprendizagem são sociais; pois o saber é adquirido no contexto de uma socialização profissional, adquirido ao longo do tempo" (TARDIF, 2008, p. 12).

Sobre isso, Tardif (2008) menciona:

Os saberes de um professor são uma realidade social materializada através de uma formação, de programas, de práticas coletivas, disciplinas escolares, e, são também, ao mesmo tempo, os saberes dele. (2008, p. 16)

Desta forma, contemplando o que já fora citado sobre formação inicial, Tardif (2008) também refere que a formação inicial esteve embasada somente a partir de conhecimento conteudistas, "conhecimentos esses produzidos geralmente numa redoma de vidro, sem nenhuma conexão com a ação profissional", fato este que traz por consequência tantas dificuldades de enfrentamento da realidade escolar que depois será vivenciada pelo docente.

Essa visão disciplinar e aplicacionista da formação profissional não tem mais sentido hoje em dia, não somente no campo do ensino, mas também em outros setores profissionais. Procuro mostrar com o conhecimento do trabalho dos professores e o fato de levar em consideração os seus saberes cotidianos permite renovar nossa concepção não só a respeito da formação deles, mas também de suas identidades, contribuições e papeis profissionais. (2008, p. 23)

É perceber que o docente não pode ser apenas um reprodutor de "saberes produzidos por outro grupo de pensadores" (TARDIF, 2008, p. 32), mas crítico e capaz de refletir as questões que se apresentam em sala de aula.

Sobre isso, Tardif (2008, p. 36-38) vai nos ensinar que nessa concepção de que o docente não é mero reprodutor de conhecimento adquirido pelo método conteudista e tecnicista, mas que seu saber é plural, é que esse demonstrará do que esse saber é composto por quatro classes de saberes:

(a) Saberes da formação profissional - conjunto de saberes transmitidos pelas instituições de formação de professores, bem como concepções que advem de reflexões da prática docente;

(b) Saberes disciplinares - saberes sociais definidos e selecionados pela instituição universitária. São as disciplinas propriamente ditas. São saberes que emergem da tradição cultural e dos grupos sociais produtores de saberes; 
(c) Saberes curriculares - dizem respeito à forma como as escolas se estruturam. São discursos, objetivos, conteúdos e métodos a partir das quais as instituições de ensino categorizam e apresentam os saberes sociais por ela defendidos e selecionados como modelos;

(d) Saberes experimentais - desenvolvidos pelos professores no âmbito de sua atuação profissional, baseados em seu trabalho cotidiano e no conhecimento de seu meio.

Dentre todos os saberes expostos, o saber experiencial, os quais "brotam da experiência e são por ela validados", são primordiais e, nas palavras de Tardif (2008):

Eles incorporam-se à experiência individual e coletiva sob a forma de habitus e de habilidades, de saber-fazer e de saber ser. (...) Surgem como núcleo vital do saber docente, núcleo a partir do qual os professores tentam transformar suas relações de exterioridade com os saberes em relações de interioridade com sua própria prática. Neste sentido, os saberes experienciais não são saberes como os demais; são, ao contrário, formados de todos os demais, mas retraduzidos, "polidos" e submetidos às certezas construídas na prática e na experiência. (2008, p. 39 e 54)

Desta forma, ao analisar o saber docente a partir da perspectiva da pluralidade, Tardif (2008) refere que além da necessidade de diversos saberes, estes devem estar articulados na formação, contemplando a noção de que o docente ao construir seu saber o faz de forma interligada com a realidade e suas vivências, exigindo do professor capacidade de dominar, integrar e mobilizar tais saberes enquanto condição para sua prática, haja vista que o docente não é constituído apenas da formação técnica, mas pela prática diária que vai moldando sua atuação, reforçando a necessidade de boa relação do docente com seu ambiente de trabalho até as informações que permeiam essa construção cotidiano do saber.

Contemplando essa gama de saberes que são construídos e adquiridos ao longo do "ser docente", de sua prática, Tardif (2008), refere que:

O professor ideal é alguém que deve conhecer sua matéria, sua disciplina e seu programa, além de possuir certos conhecimentos relativos às ciências da educação e à pedagogia e desenvolver um saber pratico baseado em uma experiência cotidiana com os alunos. (2008, p. 39)

Assim, contemplando tais ensinamentos, na perspectiva do saber docente plural e social, percebe-se o quanto os cursos de formação inicial precisam de fato articular a teoria e prática, contribuindo para que o saber docente se formule e se molde conforme suas relações com a prática, sendo que a formação de professores pode contribuir com isso se desafiar os educandos a problematizar as mais diferentes questões que estarão presentes na sala-de-aula, como as temáticas em discussão nesse artigo, gênero e diversidade.

Exemplo de que a formação inicial ainda possui uma relação arreigada de um papel conteudista aparece naquilo que Tardif (2008) vai referir como uma "relação de exterioridade", onde às Instituições formadoras cabe a produção dos saberes científicos e pedagógicos, e aos professores compete "apropriar-se desse saberes, no decorrer da formação, como normas e elementos de sua competência profissional, competência essa sancionada pela universidade e pelo estado" (TARDIF, 2008, p. 41). 
Então, aparece aqui a necessidade de que a formação docente contemple uma formação mais integrada e que o docente perceba isso em suas vivências, conseguindo fazer inter-relações e não apenas reproduzindo conteúdos ditados pelas Instituições de Ensino e que acabam desconexos com a realidade que estão inseridos.

Com isso, se percebe como essencial que o professor consiga fazer interligações uns com os outros com o intuito de dialogar com os saberes e na troca de experiências e inquietações melhorar o trabalho e fortalecer uma atuação qualificada, a partir de novas significações às suas práticas.

Nóvoa (2009) vai mencionar a importância da formação entre os docentes, citando que:

Quero sublinhar a necessidade de os professores terem um lugar predominante na formação dos seus colegas. Não haverá nenhuma mudança significativa se a "comunidade dos formadores de professores" e a "comunidade dos professores" não se tornarem mais permeáveis e imbricadas. (...) Na verdade, não é possível escrever textos atrás de textos sobre a praxis e o practicum, sobre a phronesis e a prudentia como referências do saber docente, sobre os professores reflexivos, se não concretizarmos uma maior presença da profissão na formação. É importante assegurar que a riqueza e a complexidade do ensino se tornem visíveis, do ponto de vista profissional e científico, adquirindo um estatuto idêntico a outros campos de trabalho académico e criativo. E, ao mesmo tempo, é essencial reforçar dispositivos e práticas de formação de professores baseadas numa investigação que tenha como problemática a ação docente e o trabalho escolar. Trata-se, sim, de afirmar que as nossas propostas teóricas só fazem sentido se forem construídas dentro da profissão, se forem apropriadas a partir de uma reflexão dos professores sobre o seu próprio trabalho. Enquanto forem apenas injunções do exterior, serão bem pobres as mudanças que terão lugar no interior do campo profissional docente. (2009, p. 17-18)

Desta forma, aparece como ponto também essencial que a formação docente seja realizada de forma colaborativa, pela troca de experiências e, sobretudo, diálogo. Isso porque a atuação docente só se qualificará quando for possível conversar com os pares e perceber em que aspectos é essencial uma atuação mais efetiva para um trabalho mais qualificado. Trata-se de enxergar a educação como ferramenta capaz de transformar pessoas e subsidiar um trabalho eficiente e eficaz.

Brancher et al (2007) ao refletirem sobre a formação docente, referem:

A formação profissional pressupõe o caráter contínuo, engloba a formação inicial e continuada dos professores e necessita de conhecimentos teóricos e práticos para e no exercício da docência. Aprender a ser professor não se encerra com a formação. A aprendizagem docente se dá por meio das situações práticas, que exigem deste profissional um desenvolvimento amplo, não apenas de conhecimentos, mas de atitudes, valores, bem como de capacidade de trabalho colaborativo $(2007$, p. 67)

Desta forma, dentro da perspectiva investigada por esse artigo, qual seja, a importância da formação inicial na construção dos saberes, a partir da necessidade de trabalhar questões de gênero e diversidade nos cursos de Licenciatura, tem-se como essencial o aspecto que envolve a ideia de que, de fato, a formação docente acontecerá muito mais a partir de sua prática, sendo permeada por suas atitudes e valores, aparecendo a importância de tratar de diversos assuntos enquanto aspectos latentes na sociedade como alicerce para um construto sólido e capaz de dar conta da realidade escolar. 
Ainda, após a reflexão acerca do saber docente, para finalizar tal reflexão, cita-se Nóvoa (2009), o qual abordará a respeito do bom professor. Quem seria ele? Tal problematização vem ao encontro do tema deste artigo quando se busca perceber que a construção do professor advém de seus construtos ao longo da formação inicial e, sobretudo, o construto ao longo de seu trabalho diário. Desta forma, o autor vai referir que "esta abordagem conduziu à consolidação de uma trilogia que teve grande sucesso: saber (conhecimentos), saber-fazer (capacidades), saber-ser (atitudes) (NÓVOA, 2009, p. 29).

Assim, considerando o saber docente enquanto um saber social e que abraça diferentes saberes (TARDIF, 2011), fundamental também que a formação inicial seja capaz de além de agregar o conhecimento técnico-científico, desperta capacidades e atitudes aos seus futuros docentes, com o intuito de construir um saber que abraça todos os lados e se alimente da busca pelos entendimentos e aspirações que são desencadeadas pela prática docente diária, em qualquer local de atuação, despertando a capacidade reflexiva em grupo (IMBERNÓN, 2011) enquanto processo coletivo para regular as ações.

\section{CONSIDERAÇÕES FINAIS}

A partir dos diversos pontos elencados ao longo do artigo, foi possível verificar que o IFFar trabalha no sentido de promover uma formação docente que provoque reflexões sobre questões de gênero e diversidades, embora poderia ser mais incisiva se contemplasse tais temáticas dentro de outros componentes curriculares, na forma de interdisciplinariedade. Todavia, a constituição do NUGEDIS é também uma ferramenta de formação, aparecendo como aliada nessa busca de discussão e reflexão sobre temáticas latentes e presentes no espaço escolar.

Nesse sentido, ao abordarmos a questão da importância da formação inicial enquanto etapa que busca constituir o docente, prima-se para que esta seja global, abraçando diferentes eixos de conhecimento: técnico, cultural, psicopedagógico. Uma formação que esteja conexa coma realidade e se insira nesta de modo a contribuir para um olhar diferenciado e contextualizado das demandas que a carreira docente irá permear.

Ainda, quando se discute formação inicial indubitavelmente se está construindo o saber docente, o qual por ser complexo e plural, precisa ser articulado com as questões do cotidiano, reflexo da prática docente, a qual é resultado da relação existente entre os seus diferentes saberes, adquiridos não somente na sua preparação profissional, mas resultantes dos conhecimentos aprendidos na sua vida familiar e social, no "decorrer de sua trajetória escolar como aluno, no seu próprio lugar de trabalho, por meio das relações estabelecidas com alunos e colegas de profissão"(CARDOSO et al, 2012, p. 4).

Assim, pensando-se a formação inicial aliada a realidade escolar, fundamental que esta instigue o docente a problematizar as questões de gênero e diversidade inerentes ao ambiente escolar, uma vez que este produz e reproduz muitas situações de discriminação e preconceito, sendo braço essencial nessa mediação o docente, dentro de seu saber experiencial, técnico, 
subsidiando as discussões e qualificando sua atuação dentro da escola, uma vez que a construção do saber precisa ser feita também em rede com os demais colegas de trabalho.

Fato é que temáticas como a abordado neste artigo estão no ambiente escolar, uma vez que a escola local de construção de identidades e trajetórias, precisa estar aberta a todos e construir-se em um contexto onde todos os envolvidos no processo educacional sejam percebidos, sentindo-se parte do conjunto. É entender que o contexto histórico atual traz consigo essa gama de possibilidades imersas em uma sociedade imediatista e ainda muito preconceituosa.

Assim, instrumentalizar o docente desde sua formação inicial, trazendo para suas discussões as questões de gênero e diversidade no ambiente escolar é construir um saber que estará incorporado e aberto para novas experiências e vivências, deixando de lado a insegurança por não saber como abordar os temas, mas ser de fato protagonista em momentos de sensibilização e busca de respeito e tolerância.

\section{REFERENCIAL}

Plano de Desenvolvimento Institucional do Instituto Federal de Educação, Ciência e Tecnologia Farroupilha. Disponível em: http://w2.iffarroupilha.edu.br/site/midias/arquivos/20148309056884pdi 14 18pdf.pdf. Acesso em 31 mai 2017.

Projetos Pedagógicos de Curso. Instituto Federal Farroupilha. Disponível em: http://www.iffarroupilha.edu.br/projeto-pedag\%C3\%B3gico-de-curso/sobre-os-projetospedag\%C3\%B3gicos-de-cursos. Acesso em 31 mai 2017.

BRANCHER, Vantoir Roberto; BAPTISTA, Elza Hirata; MARASCHIN, Mariglei Severo; CONCEIÇÃO, Victor Julierme Santos da. Formação do Professor: Algumas reflexões Coletivas. In Revista de Educação Educere et Educare. Unioeste. Vol. 2 no 4 jul./dez. 2007, p. 63-75. Disponível em http://e-revista.unioeste.br/index.php/educereeteducare/article/viewFile/1655/1342. Acesso em 26 jun 2017.

BRASIL. Lei 11.892 de 29 de dezembro de 2008. Institui a Rede Federal de Educação Profissional, Científica e Tecnológica, cria os Institutos Federais de Educação, Ciência e Tecnologia, e dá outras providências. Disponível em http://www.planalto.gov.br/ccivil_03/ato20072010/2008/lei//11892.htm. Acesso em 30 mai 2017

BRASIL. Ministério de Educação e Cultura. LDB - Lei no 9394/96, de 20 de dezembro de 1996. Estabelece as diretrizes e bases da Educação Nacional. Brasília : MEC, 1996.

BRASIL. Parâmetros Curriculares Nacionais para o Ensino Fundamental I. Brasília: MEC/SEF, 1997. Disponível em: http://portal.mec.gov.br/seb/arquivos/pdf/livro01.pdf Acesso em: 10 mai. 2017.

CARDOSO, Aliana Anghinoni; PINO, Mauro Augusto Burkert Del; DORNELES, Caroline Lacerca. Os saberes profissionais dos professores na perspectiva de Tardif e Gauhier: contribuições para o campo de pesquisa sobre os saberes docentes no Brasil. In IX Seminário de Pesquisa em Educação da Região Sul. Disponível em: http://www.ucs.br/etc/conferencias/index.php/anpedsul/9anpedsul/paper/viewFile/668/556. Acesso em 26 jun 2017. 
CARRARA, Sérgio. Educação, diferença, diversidade e desigualdade. Gênero e diversidade na escola: formação de professoras/es em Gênero, Orientação Sexual e Relações Étnico-Raciais. Livro de conteúdo. Versão 2009. - Rio de Janeiro : CEPESC; Brasília : SPM, 2009. Disponível em: http://estatico.cnpq.br/portal/premios/2014/ig/pdf/genero diversidade escola 2009.pdf. Acesso em: 02 jun 2017.

CUNHA, Maria Isabel. Trajetórias e lugares da formação da docência universitária da perspectiva individual ao espaço institucional. Araraquara. Junqueira \& Marin, 2010.

DELORS, Jacques. La Educación encierra un Tesoro: informe de la UNESCO de la comisión internacional para la educación para el siglo XXI. Madrid: Santillana/Ediciones UNESCO, 1994.

FREIRE, Nilcéa. SANTOS, Edson. Construindo uma política de educação em gênero e diversidade. Gênero e diversidade na escola: formação de professoras/es em Gênero, Orientação Sexual e Relações Étnico-Raciais. Livro de conteúdo. Versão 2009. - Rio de Janeiro : CEPESC; Brasília : SPM, 2009. ISBN 978-85-89737-11-1.

GAUTHIER, C. et al. Por uma teoria da pedagogia. ljuí. Unijuí. 1998

IMBERNÓN, Francisco. Formação docente e profissional: formar-se para a mudança e a incerteza. Tradução de Silvana Cobucci Leite. 9a edição. São Paulo: Cortez, 2011. In Coleção questões de nossa época; v.14. ISBN 978-85-249-1630-4

INEP. Instituto Nacional de Estudos e Pesquisas Educacionais Anísio Teixeira. http://www.inep.gov.br/

LOURO, G. L. Gênero, sexualidade e educação. Uma perspectiva pós-estruturalista. Petrópolis, RJ. Vozes, 1997. ISBN 85.326.1862-6.

NÓVOA, Antonio. Professores: o futuro ainda demora muito tempo? In Professores: Imagens do futuro presente. Educa, Lisboa, 2009.

PIMENTA, Selma Garrido (org.) Saberes pedagógicos e atividade docente. São Paulo: Cortez, 1999. (CAP 1, p. 15-34)

ROSEMBERG, F. Políticas educacionais e gênero: um balanço dos anos 1990. Cadernos Pagu (16) 2001, p. 151 - 197. Disponível em: http://www.scielo.br/pdf/cpa/n16/n16a09.pdf. Acesso em: 03 jun. 2017.

SEFFNER, F.; PICCHETTI, Y. P. A quem tudo quer saber, nada se lhe diz: uma educação sem gênero e sem sexualidade é desejável? Revista Reflexão e Ação, Santa Cruz do Sul, v. 24, n. 1, p. 61-81, Jan./Abr. 2016.

SILVA, Ariana Kelly Leandra Silva da. Diversidade Sexual e de Gênero: a construção do sujeito social. Rev. NUFEN [online]. v.5, n.1, Janeiro-Julho, 12-25, 2013. ISSN 2175-2591.

SILVÉRIO, Valter Roberto; SOUSA, Karina Almeida de; VIEIRA, Paulo Alberto Santos; RODRIGUES, Tatiane Cosentino; MOYA, Thaís Santos. O cotidiano e o futuro da educação brasileira. In Marcas da diferença no ensino escolar. São Carlos. UFSCAR, 2010. ISBN 978-85-7600-213-0.

TARDIF, Maurice. Saberes docentes e formação profissional. Petrópolis, RJ: Vozes, 2008. 